\title{
A Case of Right Sided Aortic Arch with Kommerell Diverticulum
}

\section{Arivudainambi VP* \\ Dr Mgr Medical University, India}

*Corresponding author: Arivudai Nambi Veerappan Periasamy, Dr Mgr Medical University, plot no 1203 11th cross, vasan valley, nachikurichi Trichy Tamilnadu India 620102, India, Tel: 919442399890; Email: arivudain@yahoo.com

\section{Case Report}

Volume 2 Issue 5

Received Date: September 28, 2018

Published Date: October 31, 2018

DOI: $10.23880 /$ mjccs-16000181

\section{Abstract}

Introduction: Kommerell diverticulum, a rare embryological variant, is an aneurysm of aortic arch at the origin of an aberrant subclavian artery. It is usually asymptomatic and detected incidentally on imaging studies or postmortem. Common symptoms include dysphagia and chest pain. The most common complications include rupture due to an enlarged diverticulum.

Case Report: We present a male patient evaluated for chronic chest pain following traumatic blunt injury, who was incidentally found to have right sided aortic arch with kommerell diverticulum.

Conclusion: Basic investigations like chest X-ray helps in clinching the diagnosis. Vascular anomalies like kommerell diverticulum should be considered as differential diagnosis in the evaluation of chronic cough, dysphagia, dyspnea.

Key words: Right Aortic Arch; Aberrant Subclavian Artery; Kommerell's Diverticulum

\section{Introduction}

Right aortic arch with aberrant left subclavian artery is a rare congenital defect of thoracic aorta. It is present in $0.05 \%$ to $0.1 \%$ of radiology series. This condition is asymptomatic unless aneurysmal disease develops [1]. Kommerell's aneurysm, which was first described by Burchard Kommerell in 1936 in a living patient [2].

\section{Case Report}

A 47-year-old male patient presented with a one-year history of continuous, dull aching, non-exertional left sided chest pain. He had no previous comorbid illness. Physical examination was normal except with features suggestive of periarthritis left shoulder showed normal sinus rhythm and no ST-T changes.

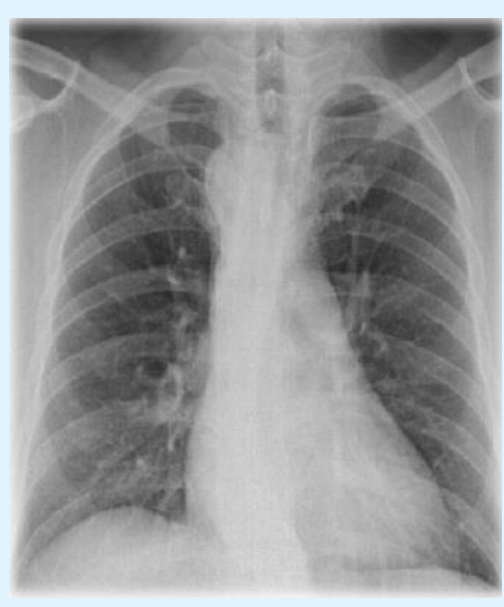

Figure 1: Chest X-ray PA view showing absent left aortic knuckle and mediastinal widening. 


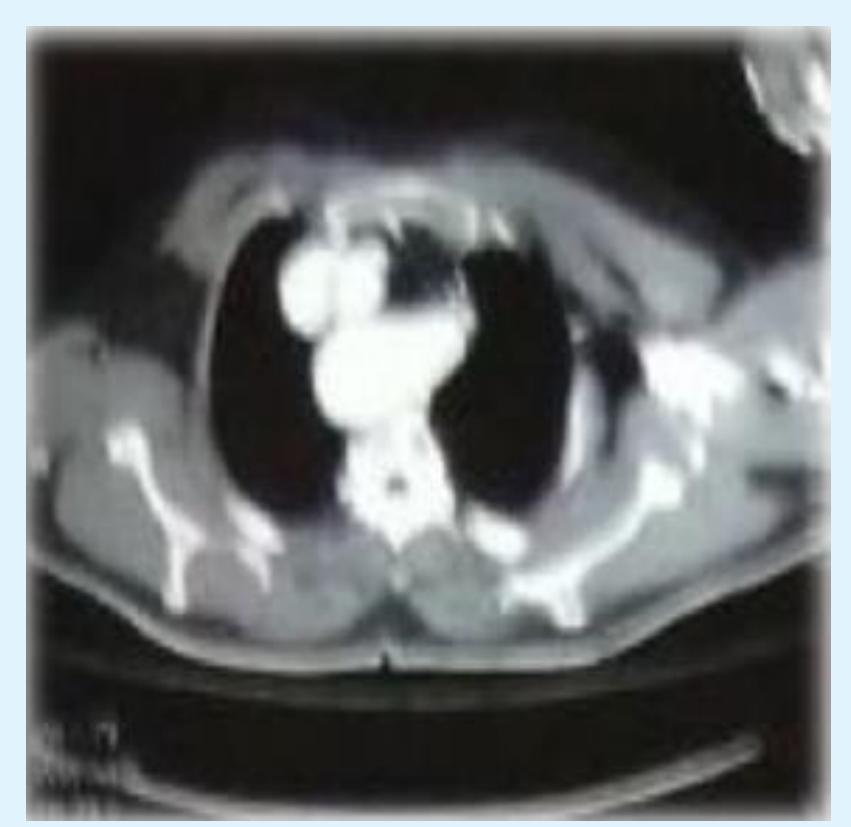

Figure 2a: CT Chest showing right sided aortic arch a) At the level of superior mediastinum.

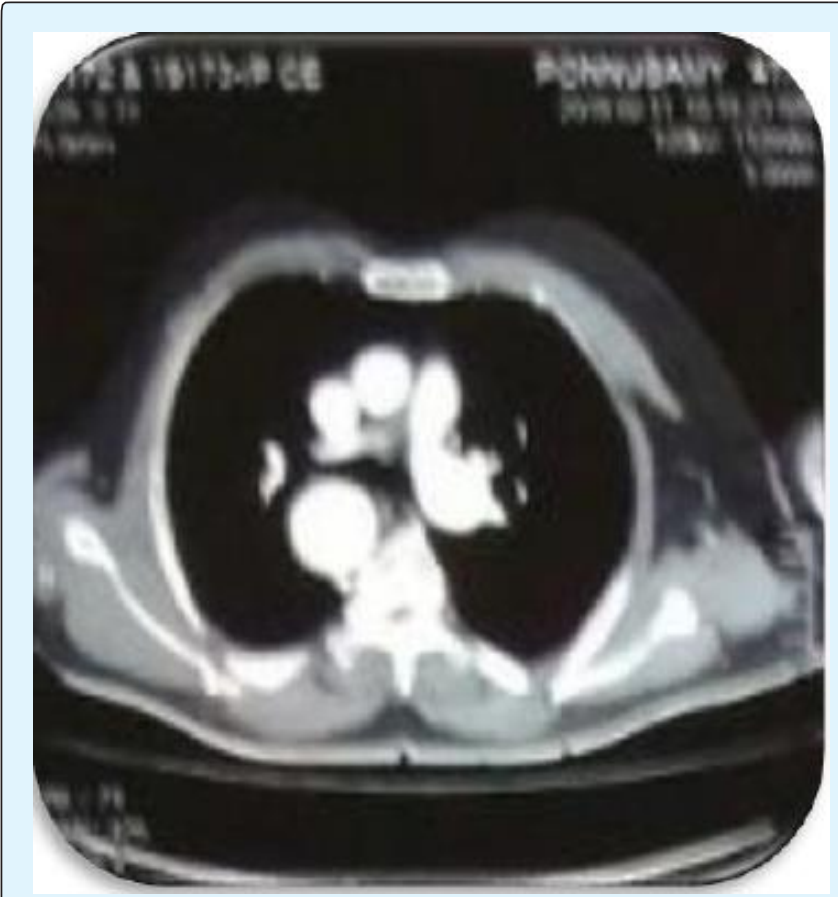

Figure 2b: a CT SCAN chest right sided aortic arch b) At the level of pulmonary artery.
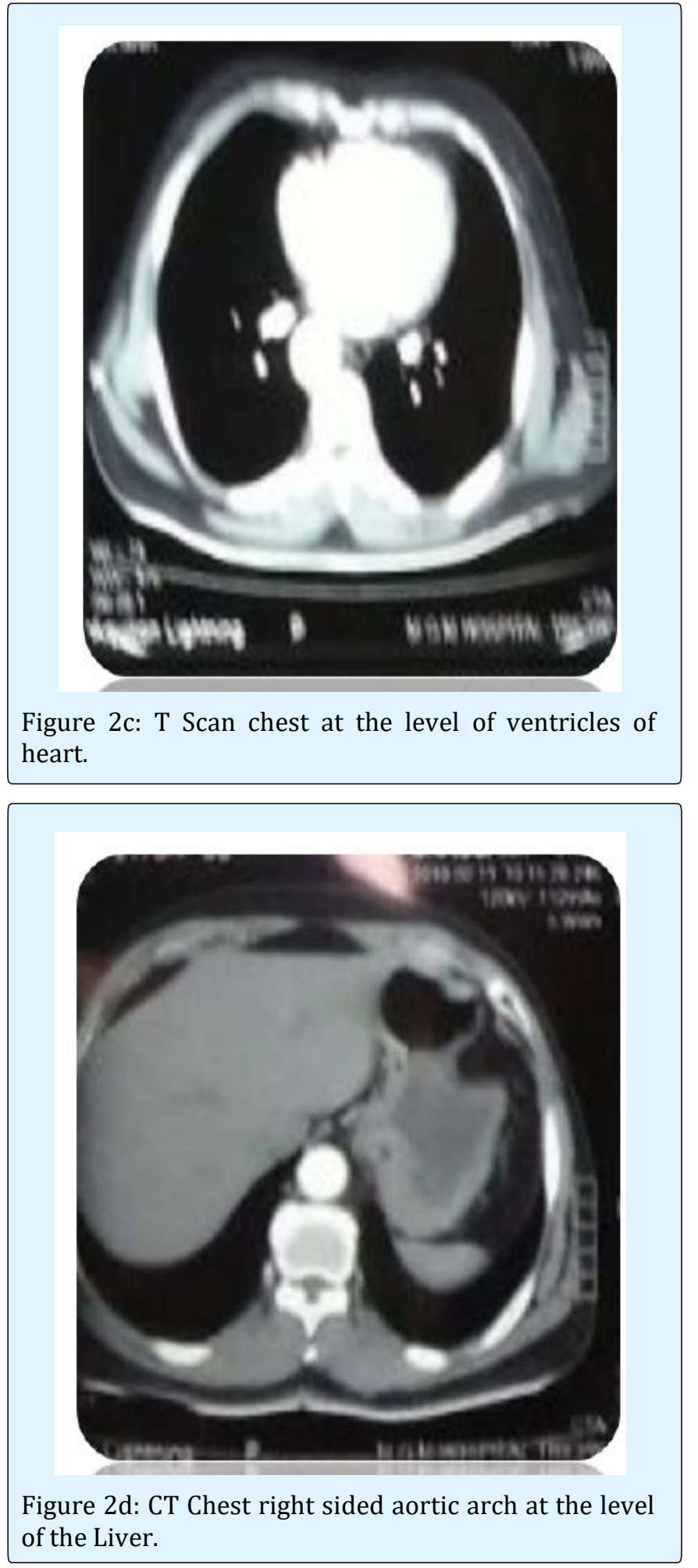

Copyright@ Arivudainambi VP. 


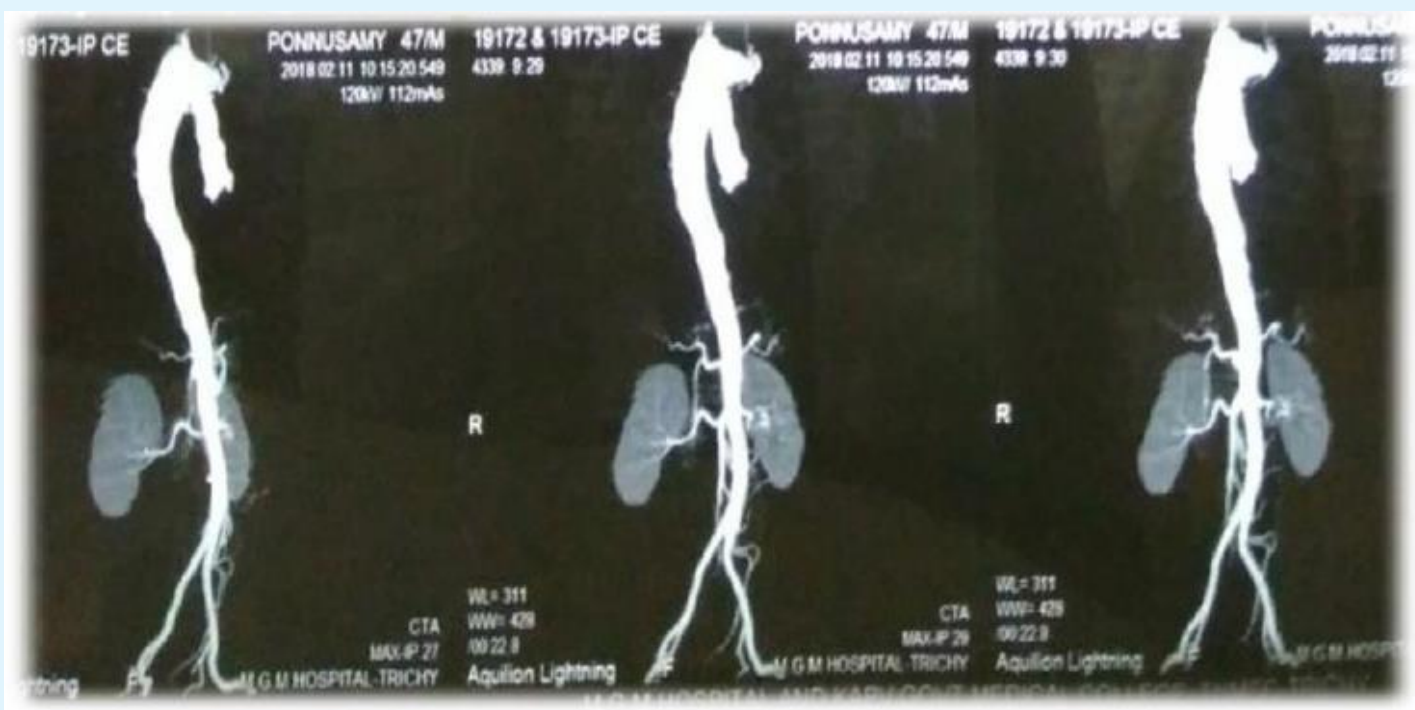

Figure 3: CT aortogram showing Type II right aortic arch with aneurysmal dilatation at the anomalous origin of left subclavian artery.

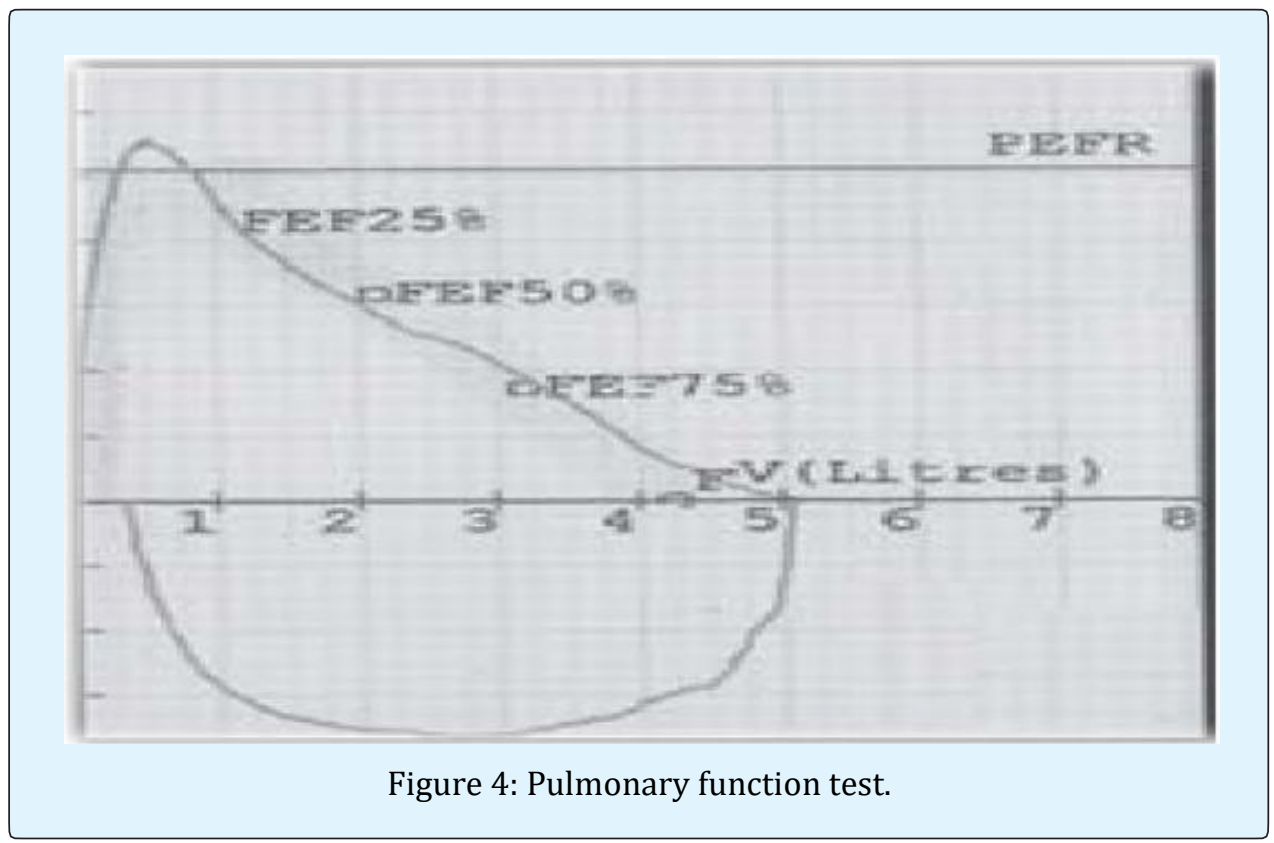

\section{Discussion on Embryology of Aorta}

Development of aorta occurs in third week of gestation with sequential formation of six pairs of arterial arches connecting the dorsal and ventral aorta. Selective regression and persistence of these arch vessels forms the major arteries of the body. $1^{\text {st }}, 2^{\text {nd }}, 5^{\text {th }}$ arterial arches disappear [3].
- $3^{\text {rd }}$ arch common carotid artery.

- $4^{\text {th }}$ arch-

Right- Proximal part of right subclavian artery.

Left - Part of aortic arch between left carotid artery and left subclavian artery.

- $6^{\text {th }}$ arch forms Pulmonary arteries and ductus arteriosus. 


\section{Medical Journal of Clinical Trials \& Case Studies}

Right proximal portion of $6^{\text {tharch }}$ forms proximal segment of right pulmonary artery.
Left proximal portion of $6^{\text {th }}$ arch forms proximal segment of left pulmonary artery while distal part of left $6^{\text {th }}$ arch forms ductus arteriosus.

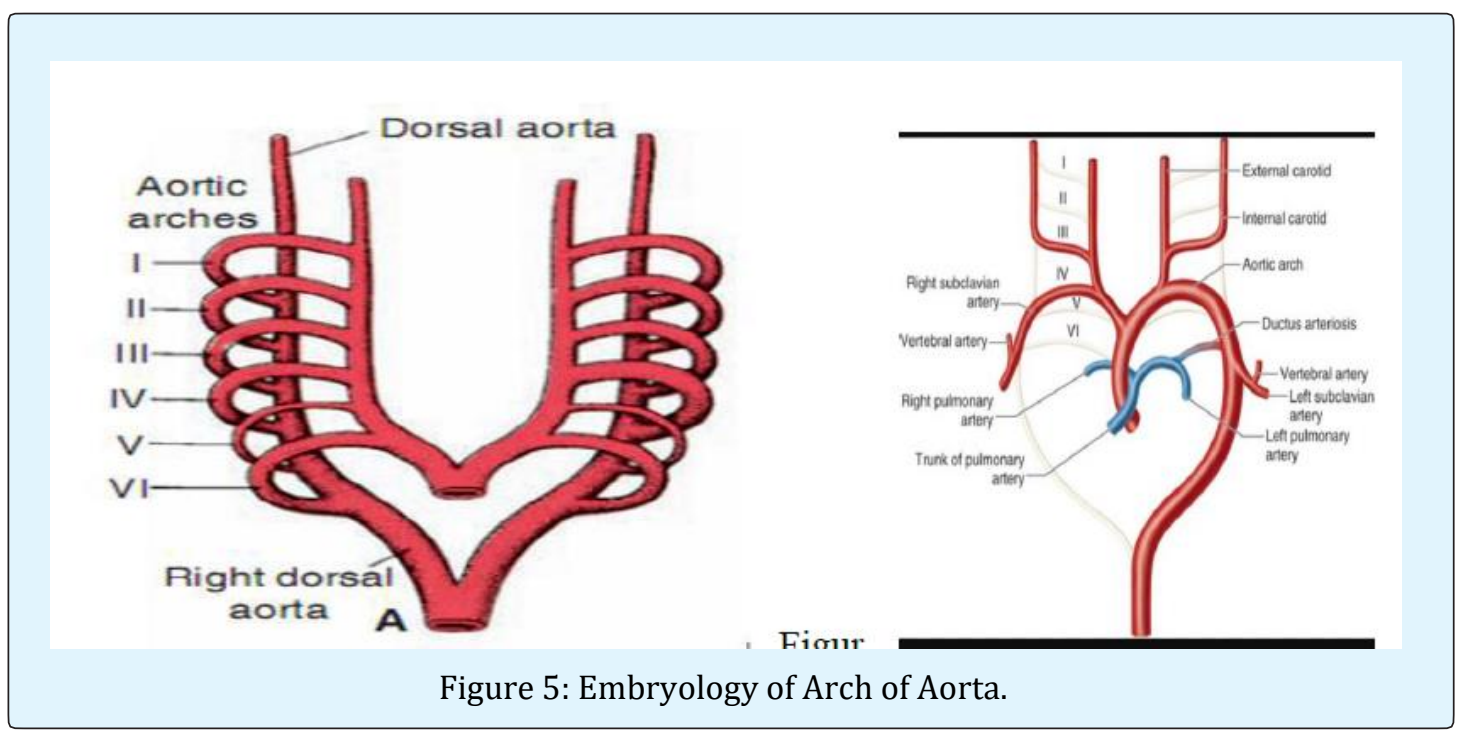

\section{Discussion}

Right aortic arch is a developmental anomaly of the thoracic aorta, caused by persistence of the right fourth branchial arch during embryogenesis. It is associated with deletion of 22q11 chromosome in $24 \%$ cases. It was first documented by Fioratti and Aglietti in 1763 [4]. This has been classified by Edward in 1948, Felson and Palayew in 1963 and Steward et al in 1964 [5,6].

\section{Edward's Classification [7]}

Type 1: Right sided aortic arch with mirror image branching due to interruption of dorsal segment of left arch between left subclavian artery and descending aorta with regression of right ductus arteriosus in hypothetical double aortic arch.

Type 2: Right aortic arch with aberrant left subclavian artery, due to interruption of dorsal segment of left arch between left common carotid artery and left subclavian artery with regression of right ductus arteriosus.

Type 3: Right aortic arch with isolated left subclavian artery, due to interruption of arch at two levels, one level between left common carotid and subclavian artery, other between distal to the attachment of left ductus. It is usually associated with vertebrobasilar insufficiency.

A type 1 and 2 form $98 \%$ of the right sided aortic arch. Type 1 right aortic arch is usually occurs with cyanotic congenital heart diseases like Tetralogy of Fallot, Truncus arteriosus [8].

Type 2 right sided aortic arch usually remains asymptomatic and there is no association with cardiac anomalies. However, more symptoms are due to atherosclerotic changes of the anomalous vessels, dissection, aneurysm with compression of adjacent structures causing dysphagia (dysphagia lusoria), dyspnea. As our patient has no symptoms related to the vascular variations, surgery was not indicated $[4,9]$.

The aberrant subclavian artery usually originates from a kommerell's diverticulum, defined as conical dilation of the proximal portion of an aberrant subclavian artery near its origin from the aorta. It is also known as "lusoria diverticulum" [4]. It is the remnant of the left fourth aortic arch in the aberrant left subclavian artery, being located behind the esophagus in $80 \%$, between the trachea and esophagus as in our case in $15 \%$ and behind the trachea in 5\% [10]. Complications include atherosclerosis, embolism, rupture and dissection [1,10]. The mean size associated with rupture is $5.8 \mathrm{~cm}$. Investigations include barium swallow esophagogram, CT scan with contrast, cardiac MRI which demonstrates both diverticulum and its effects on trachea and esophagus [1,9]. 


\section{Medical Journal of Clinical Trials \& Case Studies}

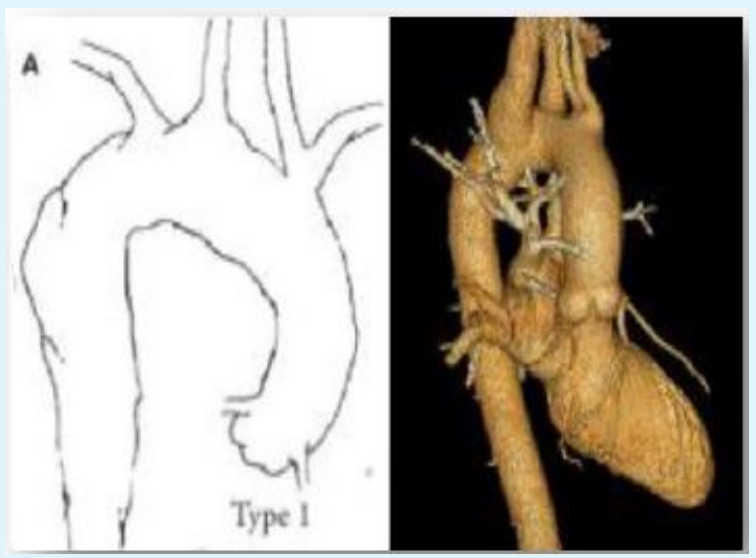

Figure 6: Type 1 right sided aortic arch with mirror image branching.

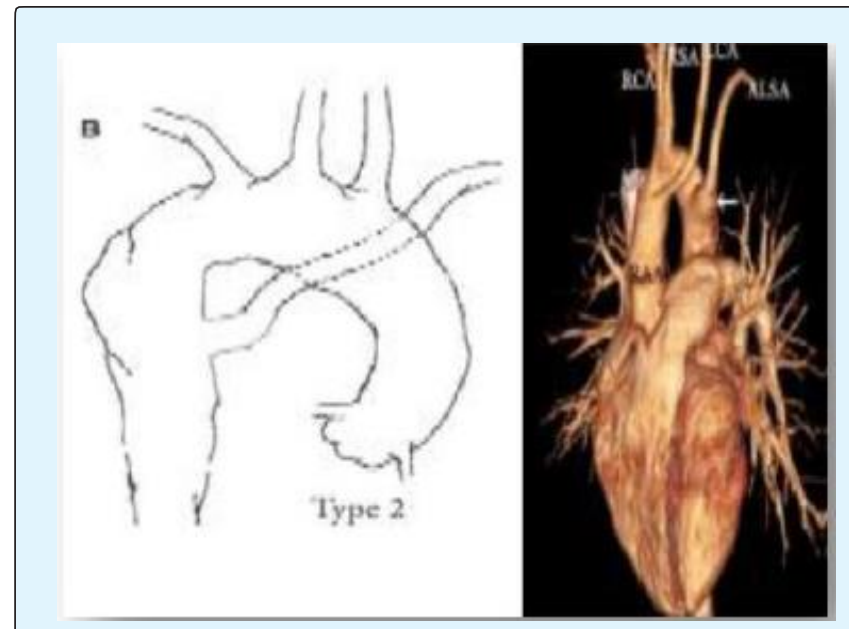

Figure 7: Type 2 Right sided aortic arch with aberrant subclavian artery.

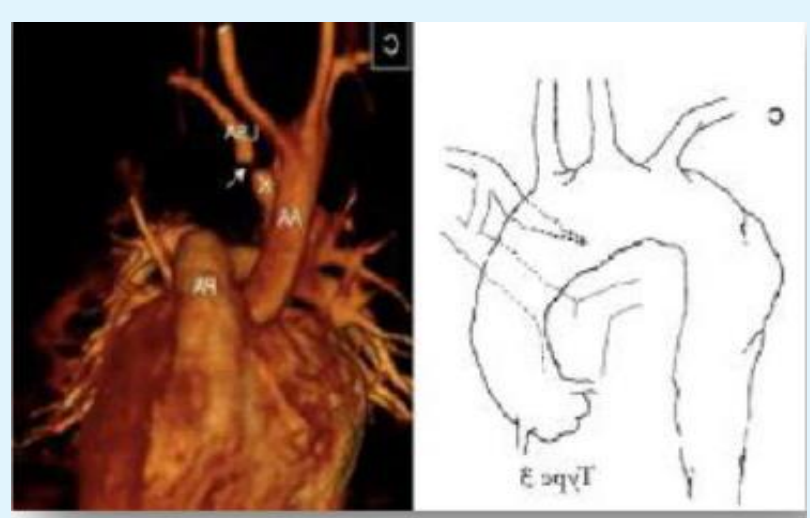

Figure 8: Type 3 Right sided aortic arch with isolated left subclavian artery.

\section{Surgical Treatment}

It is treated by excising the kommerell's diverticulum and anastomosis of the left subclavian artery to the left common carotid artery [11].

\section{References}

1. Cina CS, Althani H, Pase nau J, Abouzahi L (2004) Kommerell's diverticulum and right sided aortic arch: a cohort study and review of the literature. J Vasc Surg 39(1): 131-139.

2. Van san JA, Konstantinov IE (2002) Burckhard F. Kommerell and Kommerell's diverticulum. Tex Heart Inst J 29(2): 109-112.

3. Hazarika P, Penmetsa T, Kudva N (2017) Right-sided aortic arch with aberrant left subclavian artery and duplication of superior vena cava. J Evid Based Med Healthc 4(70): 4212-4216.

4. Kopisetty S, Bis G, Abbas AE, Dhillon RK (2015) Late presentation of right aortic arch with large left sided Kommerell's diverticulum. Int J Case Rep Images 6(8): 511-516.

5. Hastreiter AR, D'cruz IA, Cantez T, Namin EP, R Licata (1966) Right sided aorta. I. Occurrence of right aortic arch in various types of congenital heart disease. II. Right aortic arch, right descending aorta, and associated anomalies. Br Heart J 28(6): 722-739.

6. Garti IJ, Aygen MM, Vidne B, Levy MJ (1973) Right aortic arch with mirror- image branching causing vascular ring. A new classification of the right aortic arch patterns. Br J Radiol 46(542): 115-119.

7. Knight L, Edwards JE (1974) Right aortic arch. Types and associated cardiac anomalies. Circulation 50(5): 1047-1051.

8. Stewart JR, Kincaid OW, Titus JL (1966) Right aortic arch: Plain film diagnosis and significance. Am J Roentgenol Radium Ther Nucl Med 97(2): 377-389.

9. Faistauer A, Torres FS, Faccin CS (2016) Right aortic arch with aberrant left innominate artery arising from Kommerell's diverticulum. Radiol Bras 49(4): 264-266.

10. Barranhas AD, Indiani JM, Marchiori E, Santos AA, Rochitte CE, et al. (2009) Atypical presentation of 


\section{Medical Journal of Clinical Trials \& Case Studies}

Kommerell's diverticulum. Arq Bras Cardiol 93(6): e88-90, e101-103.
11. Patangi SO, Singh RK, Pauli H (2014) Right sided aortic arch with kommerell's aneurysm. Ann Card Anaesth 17: 311-313.

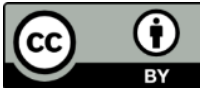

